\title{
A irradiação gama no tempo de cocção e na absorção de água em grãos de soja com e sem lipoxigenase
}

\author{
The gamma irradiation on the cooking time and absorption of water in soybean grains \\ with and without lipoxygenase
}

\author{
Luciana Marino e Biscaro ${ }^{\mathrm{I}}$ Solange Guidolin Canniatti Brazaca ${ }^{\mathrm{I}}$ Valter Arthur $^{\mathrm{II}}$ \\ Carlos Tadeu dos Santos Dias ${ }^{\text {II }}$
}

\section{RESUMO}

O processamento térmico adequado contribui para aumentar a digestibilidade e eliminar fatores antinutricionais presentes em grãos. Porém, esse processo pode ser prejudicial, causando a perda de nutrientes. A irradiação de grãos pode facilitar sua cocção, reduzindo o tempo de amolecimento. $O$ objetivo do presente trabalho foi avaliar possiveis alterações causadas pela irradiação no tempo de cocção e embebição de grãos de soja convencionais e sem lipoxigenase. As duas cultivares analisadas ('BRS 232' - com lipoxigenase e 'BRS 257' - sem lipoxigenase) diferiram entre si na quantidade de água absorvida, no tempo de embebição e no tempo de cocção dos grãos. A irradiação dos grãos, nas doses de $4 k G y$ e $8 k G y$, diminuiu a absorção de água e o tempo de cocção.

Palavras-chave: soja, lipoxigenase, irradiação, hidratação, cocção.

\section{ABSTRACT}

The appropriate heat processing helps to improve the digestibility and eliminate antinutritional factors present in grain. However, this process can be harmful, causing nutrient losses. The irradiation on grain can facilitate their cooking, and reduces the time for its softening. The objective of this study was to evaluate possible changes caused by irradiation in the time of hydration and cooking in conventional soybean and soybeans without lipoxygenase. The two cultivars ('BRS 232' - with lipoxygenase and 'BRS 257' - without lipoxygenase) differ in the amount of water absorbed, in time of hydration and time of cooking. Irradiation caused lower water absorption, but less time for cooking.

Key words: soybean, lipoxygenase, radiation, hydration, cooking.

\section{INTRODUÇÃO}

$\mathrm{O}$ processamento térmico adequado traz benefícios no que se refere aos nutrientes e à digestibilidade da soja e inativação de fatores antinutricionais (MENDES et al., 2004). Esse tratamento é usado para melhorar o valor nutricional da soja, porém, se for realizado por longos períodos e altas temperaturas, pode destruir alguns aminoácidos e diminuir a biodisponibilidade de outros nutrientes (VASCONCELOS et al., 2001).

A irradiação pode diminuir a dureza de sementes, alterando o tempo de cocção (ARMELIN et al., 2007), dependendo das características e da dose utilizada (CUNHA et al., 1993). Para grãos de feijão, com o processo de envelhecimento, ocorre o endurecimento. $\mathrm{O}$ teor de ácidos fenólicos diminuem aproximadamente 45 vezes e sua ligação com a pectina solúvel em água aumenta duas vezes. O grão endurecido tem quatro vezes menos ácido ferúlico ligado aos resíduos insolúveis da parede celular e há formação de pectatos insolúveis, degradação das células das membranas e ligações de compostos fenólicos (GARCIA et al., 1998). Essas ligações podem ser alteradas com o processo de irradiação, promovendo o amolecimento dos grãos (GARCIA et al., 1993) e facilitando o processo de cocção. O objetivo do presente trabalho foi avaliar possíveis alterações causadas pela irradiação no tempo de cocção e

\footnotetext{
'Departamento de Agroindústria, Alimentos e Nutrição, Escola Superior de Agricultura "Luiz de Queiroz" (ESALQ), Universidade de São Paulo (USP), 13418-900, Piracicaba, SP, Brasil. E-mail: sgcbraza@usp.br. *Autor para correspondência.

"Centro de Energia Nuclear na Agricultura (CENA), USP, Piracicaba, SP, Brasil.

"IIDepartamento de Ciências Exatas, ESALQ, USP, Piracicaba, SP, Brasil
} 
embebição de duas cultivares de grãos de soja, convencionais (com lipoxigenase) e sem lipoxigenase.

\section{MATERIAL E MÉTODOS}

A matéria-prima utilizada foram grãos de soja dos cultivares 'BRS 257' (ausência de lipoxigenases) e 'BRS 232' (presença de lipoxigenases), fornecidos pela EMBRAPA (Londrina/PR), da safra agrícola de 2007/ 2008. Os grãos crus foram irradiados nas doses de 4 e $8 \mathrm{kGy}$, com taxa de dose de $0,581 \mathrm{kGy}$ hora $^{-1}$ de emissão de raios gama, no CENA (Centro de Energia Nuclear na Agricultura).

A umidade inicial dos grãos crus foi medida segundo a Association of Official Analytical Chemists - AOAC (1995). O tempo de embebição dos grãos foi determinado, em triplicata, à temperatura ambiente, sendo adicionados $50 \mathrm{~mL}$ de água destilada em $10 \mathrm{~g}$ de soja. O processo de embebição foi monitorado pelas medidas de volume de água absorvida pelos grãos (mL), com intervalos de uma em uma hora, até que a leitura do volume absorvido estivesse estável em três leituras consecutivas $\left(\mathrm{mL} \mathrm{h}^{-1}\right)$, e os resultados foram expressos em mL de água absorvida, e a estabilização foi expressa em horas (MORRIS et al., 1950). Os mesmos grãos utilizados para a análise de tempo de embebição foram usados para a medida do tempo de cocção, com uso de equipamento de cocção de Mattson (BURR et al., 1968). O tempo médio de cocção foi definido como o tempo necessário para que 13 hastes perfurassem os grãos e o tempo total é o tempo necessário para que 25 hastes perfurassem os grãos.

O delineamento experimental empregado foi inteiramente ao acaso, em esquema fatorial $3 \times 2$, relacionando as três doses de irradiação empregadas e as duas cultivares. Foi realizado teste $\mathrm{F}$ e, se significativo, também foi realizado o teste de Tukey (5\%), com o programa SAS (1996).

\section{RESULTADOS E DISCUSSÃO}

A umidade dos grãos das duas cultivares de soja cruas, antes das análises, foram de 9,85 e 13,6\%, para as cultivares 'BRS 232' e '257', respectivamente.

O perfil de absorção de água pode ser observado na figura 1. Na primeira hora de análise, ocorreu a maior absorção de água pelos grãos. Em relação à absorção água absorvida, os grãos da cultivar 'BRS 232' apresentaram diferença $(\mathrm{P} \leq 0,05)$ em relação à 'BRS 257', que absorveu menos água. A velocidade de embebição da cultivar 'BRS 232' foi menor que a da 'BRS 257', já que a primeira teve tempo de embebição de 11 horas, e a outra, de 10 horas.

WANG et al. (1979) afirmaram que, nas duas primeiras horas da embebição, a absorção de água é maior e, após esse período, o volume de água absorvido por hora diminui. Além da temperatura da água de maceração, o tamanho do grão afeta a velocidade de absorção de água, indicando que grãos com maior volume apresentaram maior velocidade de embebição, embora haja também a influência da cultivar. Essa afirmação está em desacordo com os resultados obtidos (Figura 1), já que a cultivar 'BRS 232' tem tamanho superior que a 'BRS 257' e apresentou menor velocidade de embebição durante a análise. Segundo BAYRAM et al. (2004), o tempo médio de embebição da soja foi de até 12 horas, quando os grãos atingiram 134,42\% do seu peso inicial e ocorreu a estabilização da absorção

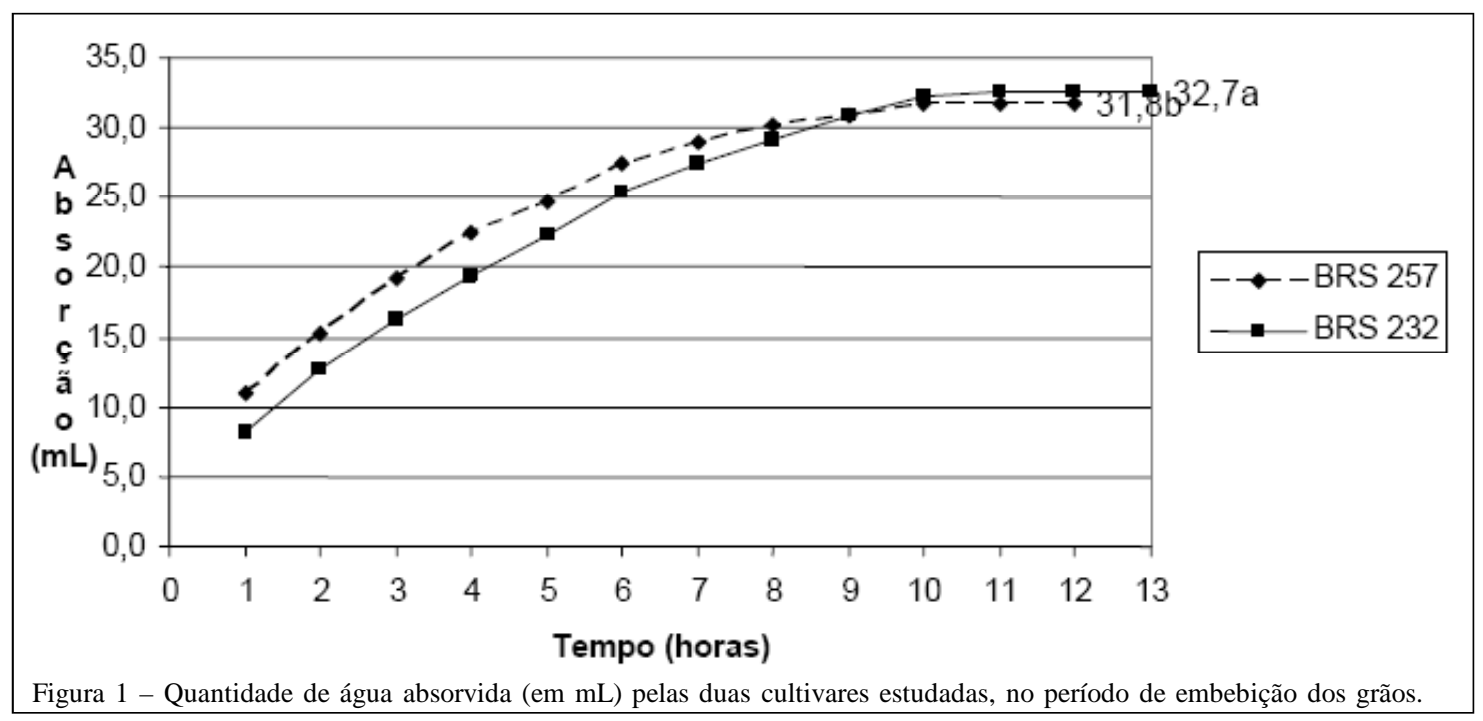

Ciência Rural, v.40, n.9, set, 2010. 
de água, similar aos resultados obtidos (Figura 1). Ocorreu a estabilização após 10 e 11 horas de embebição dos grãos, respectivamente, para as cultivares 'BRS 257' e 'BS 232'.

TOLEDO et al. (2007) analisaram cinco cultivares de soja brasileiras e, entre elas, a 'BRS 213', sem lipoxigenase, obteve a menor absorção de água $(14,3 \mathrm{~mL}$ em 8 horas), valores inferiores ao presente estudo (Figura 1). A cultivar sem lipoxigenase desse estudo absorveu mais água quando comparada à outra cultivar até a 8a hora de análise. Essa diferença pode ser explicada pela cultivar, pelo local de cultivo, pelo tempo e pelas condições de armazenamento.

VIEIRA et al. (1997), estudando as características físicas e tecnológicas de seis cultivares de soja plantadas no Brasil, encontraram tempo de estabilização de absorção de 12 a 15 horas, com quantidade de água absorvida de $125,67 \mathrm{~g}$ a $132,54 \mathrm{~g}$ de água por $100 \mathrm{~g}$ de soja. XU \& CHANG (2008) não encontraram diferenças no tempo de embebição total de grãos de soja amarelos e pretos, que foi de 16 horas.

A figura 2 mostra menor absorção de água para os grãos irradiados $(\mathrm{P} \leq 0,05)$ com o tempo de estabilização de 11 horas. Os grãos irradiados com $8 \mathrm{kGy}$ foram os que absorveram menor volume de água, e os grãos sem irradiação absorveram os maiores volumes. Todos os tratamentos diferiram entre si $(\mathrm{P} \leq 0,05)$. Os resultados obtidos (Figura 2) diferem dos dados obtidos por CARVALHO et al. (1991), provavelmente devido a diferentes doses de irradiação utilizadas e também à diferença de cultivar, solo, tratos culturais, época de plantio e outros fatores.

TOLEDO et al. (2007) verificaram que a quantidade de água absorvida por grãos de soja irradiados com 8kGy $(15,6 \mathrm{~mL})$ não diferiu dos irradiados com 4kGy (15,4mL). Grãos irradiados com doses de 2kGy e controle (sem iradiação) absorveram $15,3 \mathrm{~mL}$ e não diferiram dos tratamento com $4 \mathrm{kGy}$, mostrando que há necessidade de doses acima de $4 \mathrm{kGy}$ para obter diferença significativa.

ARMELIN et al. (2007), estudando as alterações em grãos de feijões submetidos a diferentes doses de radiação gama, verificaram que, para todos os tratamentos (controle, 2, 4, 6 e 10kGy), não houve diferença no tempo de embebição dos grãos, provavelmente devido à diferença na composição das diferentes leguminosas.

A figura 3 mostra o perfil de cocção das diferentes cultivares estudadas. A cultivar 'BRS232' apresentou tempo médio de cocção menor do que a 'BRS257' ( $\mathrm{P} \leq 0,05)$. Durante todo o processo de cocção, a 'BRS232' apresentou tempo menor para a perfuração dos grãos.

TOLEDO et al. (2007) estudaram cinco variedades de grãos de soja, entre elas a variedade 'BRS 213', sem lipoxigenase. Essa cultivar apresentou o segundo maior tempo de cocção entre todas as estudadas e não diferiu de algumas cultivares convencionais, o que indica que a presença/ausência das enzimas não influenciaram essa variável. VIEIRA et al. (1997), estudando a caracterização física e tecnológica de seis cultivares de soja plantadas no Brasil, observaram que o tempo de cocção das cultivares variou de 155 a 219 minutos. O tempo de cozimento do estudo foi definido como o tempo no qual $80 \%$ dos grãos de soja são penetrados pelas hastes do aparelho, ou seja, 20 hastes.

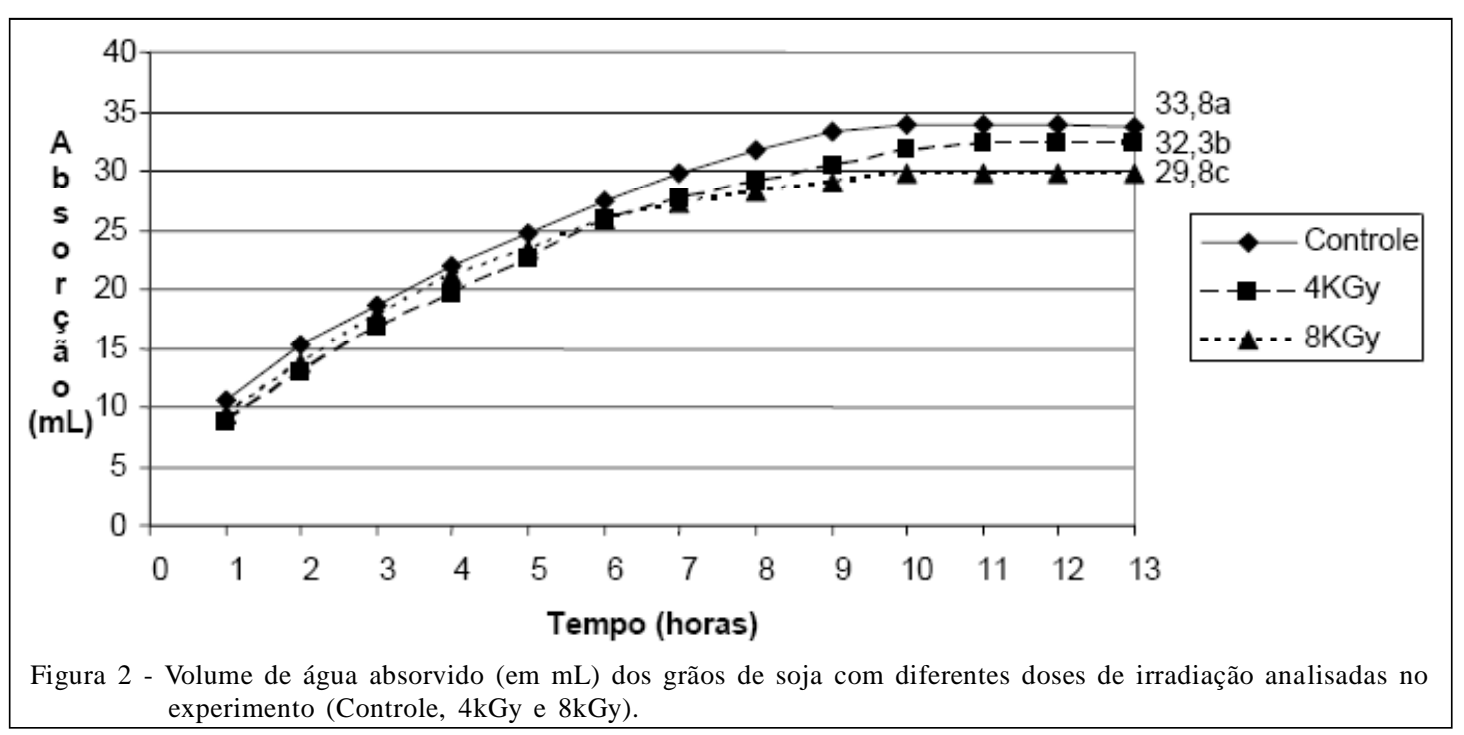

Ciência Rural, v.40, n.9, set, 2010. 


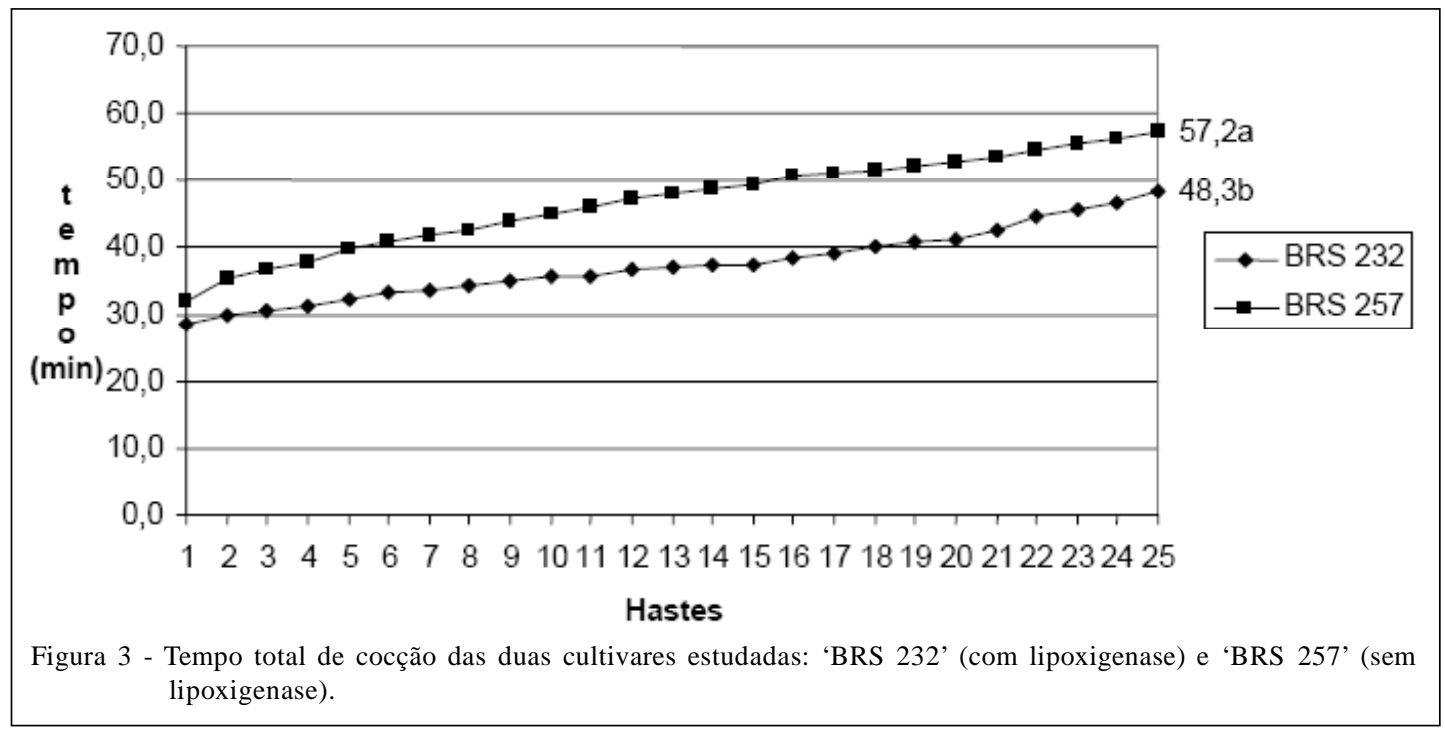

A figura 4 apresenta o tempo de cocção (h) dos grãos nas diferentes doses de irradiação. Todas as amostras apresentaram diferenças significativas. As amostras irradiadas apresentaram menor tempo de cocção $(\mathrm{P} \leq 0,05)$. Assim, quanto maior a dose de irradiação, menor o tempo de cocção dos grãos.

Para feijões irradiados com 0,5kGy e 1,0kGy, o tempo de cocção é também inferior do controle, e os feijões irradiados não diferiram entre si, tendo um tempo de cocção de 23 minutos, enquanto o controle foi de 61 minutos (CARVALHO et al., 1991). Os resultados (Figura 4) também estão de acordo com os de TOLEDO et al. (2007), que observaram diminuição no tempo de cocção de grãos de soja com o aumento das doses de irradiação, que variou de $0 \mathrm{kGy}$ a $8 \mathrm{kGy}$.
ARMELIN et al. (2007) não encontraram diferenças entre os tempos de cocção de feijões irradiados com 1, 2, 6 e 10kGy, porém o controle apresentou maior tempo de cocção. Já MANCINIFILHO (1990), também estudando feijões, mostrou que a irradiação com dose de 10kGy promoveu reduções de $50 \%$ ou mais no tempo de cocção, como os dados apresentados na figura 4.

Na comparação das cultivares, a variedade 'BRS 232' apresentou o menor tempo de cocção $(\mathrm{P} \leq 0,05)$. Já em relação ao tratamento de irradiação, quanto maior a dose, menor o tempo médio de cocção $(\mathrm{P} \leq 0,05)$ (Tabela 1).

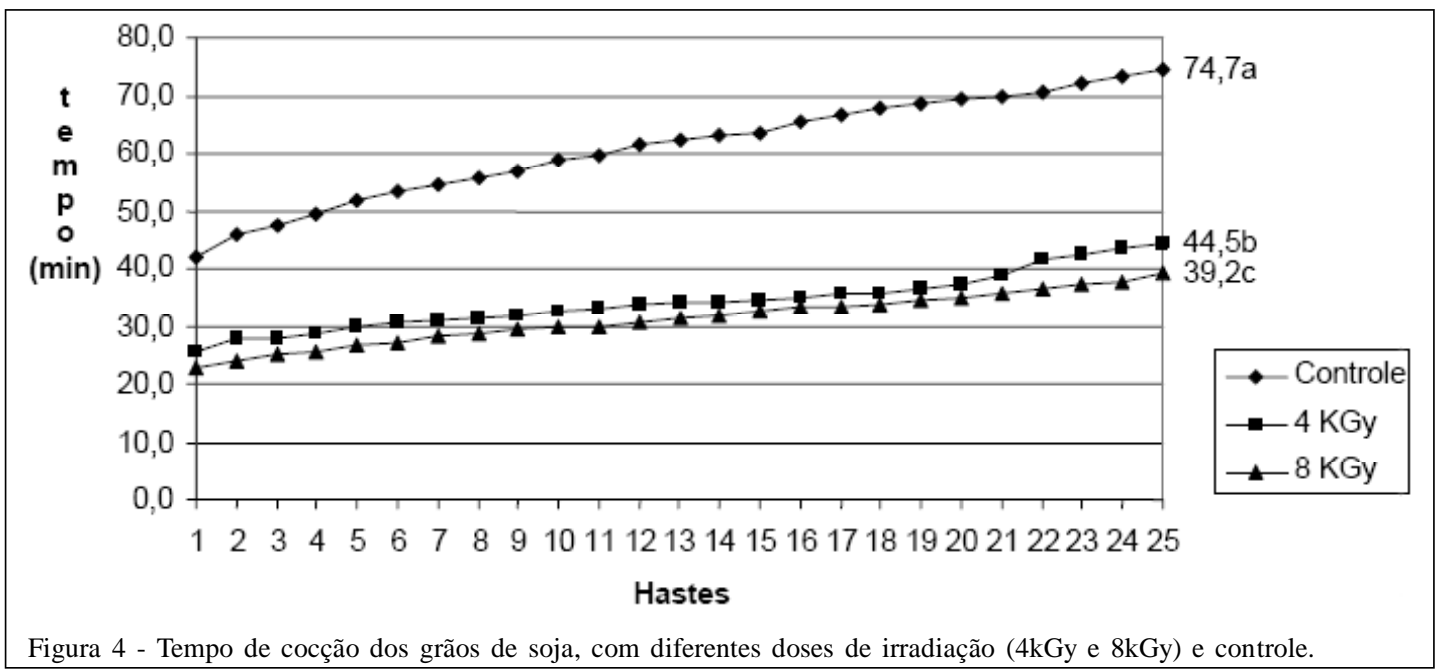

Ciência Rural, v.40, n.9, set, 2010. 
Tabela 1 - Tempo médio de cocção dos grãos, nas diferentes doses de irradiação estudadas (4kGy e 8kGy), e grupo de controle.

\begin{tabular}{llccc}
\hline Cultivares & Controle & $4 \mathrm{kGy}$ & $8 \mathrm{kGy}$ & Média das cultivares \\
\hline 'BRS 232' & $47,3 \pm 1,2^{\mathrm{la} 2}$ & $34,3 \pm 0,6$ & $29,7 \pm 1,2$ & $37,1 \pm 8,0^{\mathrm{B} 3}$ \\
'BRS 257' & $77,3 \pm 1,5$ & $34,0 \pm 1,0$ & $33,0 \pm 1,0$ & $48,1 \pm 21,9^{\mathrm{A}}$ \\
Média doses & $62,3 \pm 16,5^{\mathrm{a}}$ & $34,2 \pm 0,8^{\mathrm{b}}$ & $31,3 \pm 2,1^{\mathrm{c}}$ & \\
\hline
\end{tabular}

${ }^{1}$ média \pm desvio padrão

${ }^{2}$ médias com letras minúsculas diferentes na horizontal diferem significativamente com nível de $\mathrm{P}=0,05$.

${ }^{3}$ médias com letras maiúsculas diferentes na vertical diferem significativamente com nível de $\mathrm{P}=0,05$.

ARMELIN et al. (2007) encontraram tempo médio de 40,34 minutos de cocção para feijão não irradiado e aproximadamente 24, 22, 15 e 14 minutos para grãos irradiados com 1, 2, 6 e 10kGy, respectivamente. Os resultados de tempo de cocção média das cinco cultivares de soja estudadas por TOLEDO et al. (2007) apresentaram tempos de cocção superiores, com média variando de 193,87 minutos, no grupo controle, a 132,53 minutos, para os grãos irradiados com 8kGy, provavelmente devido ao maior tempo de armazenamento utilizado por TOLEDO et al. (2007).

Para as amostras que receberam diferentes doses de irradiação e no controle (sem irradiação), pode ser verificada diferença significativa entre elas $(P \leq 0,05)$ (Tabela 2). Também pode ser observada diferença significativa $(\mathrm{P} \leq 0,05)$ entre as cultivares, e os grãos da cultivar 'BRS232' apresentaram o menor tempo total de cocção. O comportamento do tempo médio (Tabela 1) e o tempo total (Tabela 2) de cocção foram semelhantes.
Conforme aumentou a dose de irradiação, o tempo total de cocção diminuiu, fato que também foi observado por TOLEDO et al. (2007); porém, o tempo total de cocção encontrado (TOLEDO et al., 2007) para essas cultivares foi muito superior ao do apresentado (Tabela 2), provavelmente devido ao tempo de armazenamento dos grãos.

\section{CONCLUSÃO}

Nas condições do experimento realizado, pode-se concluir que as cultivares, com e sem lipoxigenase, apresentaram diferenças significativas para o tempo de embebição e para a quantidade de água absorvida. Os grãos de soja da cultivar 'BRS 232' (com lipoxigenase) apresentaram os menores tempos de cocção e a menor quantidade de água absorvida quando comparados com os grãos da cultivar 'BRS 257' (sem lipoxigenase). Já em relação ao tratamento de irradiação, este causou diminuição na quantidade de água absorvida pelos grãos e também diminuição no tempo de cocção.

Tabela 2 - Tempo total de cocção dos grãos, nas diferentes doses de irradiação estudadas (4kGy e 8kGy), e grupo controle.

\begin{tabular}{clccc}
\hline Cultivares & Controle & $4 \mathrm{kGy}$ & $8 \mathrm{kGy}$ & Média Cultivares \\
\hline 'BRS 232' & $60,0 \pm 3,5^{\mathrm{la} 2}$ & $47,0 \pm 0,0$ & $38,0 \pm 2,0$ & $48,3 \pm 9,8^{\mathrm{B} 3}$ \\
'BRS 257' & $89,3 \pm 0,6$ & $42,0 \pm 1,0$ & $40,3 \pm 0,6$ & $57,2 \pm 24,1^{\mathrm{A}}$ \\
Média doses & $74,7 \pm 16,2^{\mathrm{a}}$ & $44,5 \pm 2,8^{\mathrm{b}}$ & $39,2 \pm 1,8^{\mathrm{c}}$ & \\
\hline
\end{tabular}

${ }^{1}$ média \pm desvio padrão.

${ }^{2}$ médias com letras minúsculas diferentes na horizontal diferem significativamente com nível de $\mathrm{P}=0,05$.

${ }^{3}$ médias com letras maiúsculas diferentes na vertical diferem significativamente com nível de $\mathrm{P}=0,05$. 


\section{REFERÊNCIAS}

ARMELIN, J.M. et al. Avaliação física de feijão carioca irradiado. Ciência e Tecnologia de Alimentos, Campinas, v.27, n.3, p.498-502, 2007. Disponível em: <http:// www.scielo.br/pdf/cta/v27n3/a12v27n3.pdf >. Acesso em: 03 ago. 2010. doi: 10.1590/S0101-20612007000300012.

ASSOCIATION OF OFFICIAL ANALYTICAL CHEMISTS AOAC. Official methods of analysis. 16.ed. Washington, 1995. 2v. (loose-leaf).

BAYRAM, M. et al. Influence of soaking on the dimensions and colour of soybean for bulgur production. Journal of Food Engineering, Oxford, v.61, n.3, p.331-339, 2004. Disponível em: $<$ http://www.scielo.br/scielo.php?script=sci_arttext\&pid=S0101$20611997000300019 \& \operatorname{lng}=$ pt\&nrm=iso\&tlng=pt $>$. Acesso em: 03 ago. 2010. doi: 10.1016/S0260-8774(03)00137-7.

BURR, H.R. et al. Cooking rates of dry beans as influenced by moisture content and temperature and time of storage. Food Technology, Chicago, v.22, n.3, p.336-338, 1968.

CARVALHO, M.R.B. et al. Efeitos da irradiação (raios ?) sobre as propriedades físicas, sensoriais e nutritivas dos grãos de feijão. Pesquisa Agropecuária Brasileira, Brasília, v.26, n.10, p.16631672, 1991. Disponível em: <http://webnotes.sct.embrapa.br/pab/ pab.nsf/FrAnual>. Acesso em: 03 ago. 2010

CUNHA, M.F. et al. Effects of pretreatment with gamma rays or microwave on storage stability of dry beans. Journal of Agricultural and Food Chemistry, Easton, v.41, n.10, p.1710-1715, 1993. Disponível em: <http://pubs.acs.org/doi/ pdf/10.1021/jf00034a036>. Acesso em: 03 ago. 2010. doi:10.1021/jf00034a036.

GARCIA, E. et al. A comparative study of normal and hard-tocook Brazilian common bean (Phaseolus vulgaris): ultrastructural and histochemical aspects. Food Structure, Chicago, v.12, n.2, p. 147-154, 1993. Disponível em: <http:/ /cat.inist.fr/?aModele $=$ afficheN\&cpsidt $=3909064>$. Acesso em: 03 ago. 2010.

GARCIA, E. et al. Hard to cook beans (Phaseolus vulgaris): Involvement of phenolic compounds and pectates. Journal of Agricultural and Food Chemistry, Easton, v.46, n.6, p.2110-2116, 1998. Disponível em: <http://pubs.acs.org/doi/ pdf/10.1021/jf970848f >. Acesso em: 03 ago. 2010. doi: $10.1021 /$ jf $970848 f$.

MANCINI-FILHO, J. Efeito das radiações gama sobre algumas características físico-químicas e nutricionais de feijões (Phaseolus vulgaris L.) armazenados. 1990. $100 \mathrm{f}$.
Tese (Livre Docência) - Faculdade de Ciências Farmacêuticas, Universidade de São Paulo, SP.

MENDES, W.S. et al. Composição química e valor nutritivo da soja crua e submetida a diferentes processamentos térmicos para suínos em crescimento. Arquivo Brasileiro de Medicina Veterinária e Zootecnia, Belo Horizonte, v.56, n.2, p.207213, 2004. Disponível em: <http://www.scielo.br/pdf/abmvz/ v56n2/20331.pdf>. Acesso em: 03 ago. 2010. doi: 10.1590/ S0102-09352004000200011.

MORRIS, H.J. et al. Processing quality of varieties and strains of dry beans. Food Technology, Chicago, v.4, n.7, p.247-251, 1950 .

STATISTICAL ANALYSIS SYSTEM INSTITUTE. Sas/Qc software: usage and reference. 2.ed. Cary, 1996. 2v. (version $6)$.

TOLEDO, T.C.F. et al. Efeito da radiação gama na absorção de água e no tempo de cocção de cultivares de soja. Bragantia, Campinas, v.66, n.4, p.565-570, 2007. Disponível em: <http:/ /www.scielo.br/pdf/brag/v66n4/05.pdf >. Acesso em: 03 ago. 2010. doi:10.1590/S0006-87052007000400005.

VASCONCELOS, I.M. et al. Nutritional study of two Brazilian soybean (Glycine max) cultivars differing in the contents of antinutritional and toxic proteins. Journal of Nutrition and Biochemistry, Amsterdam, v.12, n.1, p.55-62, 2001. Disponível em: <http:// www.sciencedirect.com/science?_ob=MImg\&_imagekey=B6T8P429XW91-8-1\&_cdi $=5092 \&$ \&user $=5674931 \&$ \&ii $=$ S 0955 $286300001480 \&$ orig=browse\&_coverDate $=01 \% 2 \mathrm{~F} 3$ $1 \% 2 F 2001 \& \_s k=999879998 \& v i e w=c \& w c h p=d G L z V l z-$ zSkzk\&md5=7613faaf7e $085 \mathrm{fbc} 531459 \mathrm{bfc} 4 \mathrm{c} 510 \mathrm{a} 4 \& \mathrm{ie}=/$ sdarticle.pdf $>$. Acesso em: 03 ago. 2010. doi:10.1016/S09552863(00)00148-0.

VIEIRA, C.R. et al. Caracterização física e tecnológica de seis cultivares de soja plantadas no Brasil. Ciência e Tecnologia de Alimentos, Campinas, v.17, n.3, p.291-294, 1997. Disponível em: <http:// www.scielo.br/scielo.php?script=sci_arttext $\&$ pid $=$ S0 101 $20611997000300019 \& \operatorname{lng}=\mathrm{pt} \& \mathrm{nrm}=\mathrm{iso} \& \operatorname{lng}=\mathrm{pt}>$. Acesso em: 03 ago. 2010. doi: 10.1590/S0101-20611997000300019.

WANG, H.L. et al. Hydration of whole soybeans affects solid losses and cooking quality. Journal of Food Science, Champaign, v.44, n.5, p.1510-1513, 1979.

XU, B.; CHANG, S.K.C. Total phenolics, phenolic acids, isoflavones, and anthocyanins and antioxidant properties of yellow and black soybeans as affected by thermal processing. Journal of Agricultural and Food Chemistry, Easton, v.56, n.16, p.7165- 7175, 2008. Disponível em: <http://pubs.acs.org/ doi/pdf/10.1021/jf8012234>. Acesso em: 03 ago. 2010. doi: $10.1021 /$ jf 8012234 . 